\title{
Application of Hybrid Lidar-Radar Technology to a Laser Line Scan System
}

\author{
Linda J. Mullen \\ EO Sensors Branch Code 4.5.5.6 \\ Building 2185 Suite 1100 \\ Naval Air Warfare Center Aircraft Division \\ 22347 Cedar Point Road Unit 6 \\ Patuxent River, MD 20670-1161 \\ phone: (301) 342-2021 fax: (301) 342-2030 email: MullenLJ@navair.navy.mil \\ Award Number: N0001499WX30165 \\ http://www.nawcad.navy.mil
}

\section{LONG-TERM GOALS}

The long term goal of this program is to improve the CSS/Raytheon Electro-Optic Identification (EOID) Sensor performance in turbid water and high solar background environments.

\section{OBJECTIVES}

The objective of this program is to investigate the application of hybrid lidar-radar technology to a laser line scan system to enhance detection sensitivity in turbid water and high solar background environments. The results will be transitioned to the CSS/Raytheon EOID Sensor Project for mine identification.

\section{APPROACH}

This project will focus on the application of the hybrid lidar-radar approach to a laser line scanner (LLS). The hybrid lidar-radar technique combines the optical propagation characteristics of light detecting and ranging (lidar) with the modulation, detection, and signal processing schemes of microwave radar. Both laboratory tank experiments and in-situ measurements will be conducted to test a modulated LLS sensor that has similar characteristics to the CSS/Raytheon EOID Sensor. The new system will be compared to its unmodulated counterpart in terms of backscatter and blur/glow/forward scatter signal levels and solar ambient noise. The results, along with input from CSS and Raytheon, will be used to select components for a modulated version of the EOID sensor. Tests will be conducted with the modified EOID sensor to collect both modulated and unmodulated images of underwater objects. Concurrent with these experiments, higher modulation frequencies and coherent detection schemes will be investigated to determine whether more advanced system configurations would further improve EOID sensor performance. Inputs from Drexel University on the current state-of-the-art in modulated transmitter and receiver components will be requested for this task. A Monte Carlo simulation has been modified to include the characteristics and geometry of the modulated laser line scanner prototype. The experimental parameters, including water clarity (b and c), target depth and reflectivity, and receiver aperture and field of view, will be used as inputs to the simulation and the impulse response of the system will be calculated. Monte Carlo simulation results will be compared with measurements and will be used to predict future experimental results. 


\section{Report Documentation Page}

Form Approved

OMB No. 0704-0188

Public reporting burden for the collection of information is estimated to average 1 hour per response, including the time for reviewing instructions, searching existing data sources, gathering and maintaining the data needed, and completing and reviewing the collection of information. Send comments regarding this burden estimate or any other aspect of this collection of information,

including suggestions for reducing this burden, to Washington Headquarters Services, Directorate for Information Operations and Reports, 1215 Jefferson Davis Highway, Suite 1204, Arlington

VA 22202-4302. Respondents should be aware that notwithstanding any other provision of law, no person shall be subject to a penalty for failing to comply with a collection of information if it

does not display a currently valid OMB control number.

\begin{tabular}{|c|c|c|}
\hline $\begin{array}{l}\text { 1. REPORT DATE } \\
\text { 30 SEP } 1999\end{array}$ & 2. REPORT TYPE & $\begin{array}{l}\text { 3. DATES COVERED } \\
\mathbf{0 0 - 0 0 - 1 9 9 9} \text { to 00-00-1999 }\end{array}$ \\
\hline \multirow{3}{*}{\multicolumn{2}{|c|}{$\begin{array}{l}\text { Application of Hybrid Lidar-Radar Technology to a Laser Line Scan } \\
\text { System }\end{array}$}} & 5a. CONTRACT NUMBER \\
\hline & & 5b. GRANT NUMBER \\
\hline & & 5c. PROGRAM ELEMENT NUMBER \\
\hline \multirow{3}{*}{\multicolumn{2}{|c|}{ 6. AUTHOR(S) }} & 5d. PROJECT NUMBER \\
\hline & & 5e. TASK NUMBER \\
\hline & & 5f. WORK UNIT NUMBER \\
\hline \multicolumn{2}{|c|}{$\begin{array}{l}\text { 7. PERFORMING ORGANIZATION NAME(S) AND ADDRESS(ES) } \\
\text { Naval Air Warfare Center Aircraft Division,EO Sensors Branch Code } \\
\text { 4.5.5.6,22347 Cedar Point Road Unit 6,Patuxent River,MD,20670-1161 }\end{array}$} & $\begin{array}{l}\text { 8. PERFORMING ORGANIZATION } \\
\text { REPORT NUMBER }\end{array}$ \\
\hline \multirow{2}{*}{\multicolumn{2}{|c|}{ 9. SPONSORING/MONITORING AGENCY NAME(S) AND ADDRESS(ES) }} & 10. SPONSOR/MONITOR'S ACRONYM(S) \\
\hline & & $\begin{array}{l}\text { 11. SPONSOR/MONITOR'S REPORT } \\
\text { NUMBER(S) }\end{array}$ \\
\hline
\end{tabular}

12. DISTRIBUTION/AVAILABILITY STATEMENT

Approved for public release; distribution unlimited

13. SUPPLEMENTARY NOTES

14. ABSTRACT

15. SUBJECT TERMS

16. SECURITY CLASSIFICATION OF:

\begin{tabular}{c|c|c}
$\begin{array}{c}\text { a. REPORT } \\
\text { unclassified }\end{array}$ & $\begin{array}{c}\text { b. ABSTRACT } \\
\text { unclassified }\end{array}$ & $\begin{array}{c}\text { c. THIS PAGE } \\
\text { unclassified }\end{array}$
\end{tabular}

17. LIMITATION OF ABSTRACT

Same as

Report (SAR)
18. NUMBER 19a. NAME OF

OF PAGES RESPONSIBLE PERSON

6 


\section{WORK COMPLETED}

The first task consisted of investigating the characteristics (receiver field of view, transmitted beam spot size and divergence, detector aperture and receiver bandwidth) of the CSS/Raytheon EOID Sensor. A nonscanning mock-up of a modulated EOID sensor was then developed with off-the-shelf components. The prototype was designed so that several issues could be addressed in the experiments, including the dynamic range of the photodetector and the effect of modulation frequency, water clarity, and solar background level on the system performance.

Tank experiments were conducted with the modulated EOID prototype. The DC and AC components of the modulated optical signal reflected from two different targets (white and black) were measured after successive additions of a scattering agent (Maalox) to the tank water and at different ambient light levels. For the AC component, both the amplitude and phase of the target reflection was measured. The contrast of the white relative to the black target was calculated from the $\mathrm{DC}$ and $\mathrm{AC}$ amplitude data, and the range of the white target was calculated from the $\mathrm{AC}$ phase data. Three modulation frequencies $(10,50$, and $90 \mathrm{MHz})$ and two different transmitter-receiver separations $(0.2$ and $0.4 \mathrm{~m})$ were used in the measurements. The results are discussed in the next section. Results from the Monte Carlo simulation are currently being analyzed and compared to experimental measurements.

\section{RESULTS}

The target contrast results are shown in Fig. 1 where the contrast for the DC (LLS) and the AC (modulated LLS) signal components are plotted as a function of the beam attenuation coefficient for two different transmitter-receiver separations $-0.4 \mathrm{~m}$ (Fig. 1a) and $0.2 \mathrm{~m}$ (Fig. 1b). For both cases, the $10 \mathrm{MHz}$ and DC contrasts overlap throughout the range of water clarities tested. This is due to the fact that the $10 \mathrm{MHz}$ wavelength $(30 \mathrm{~m})$ is significantly longer than the roundtrip tank length, $2 L_{t}=7.3 \mathrm{~m}$. For backscatter cancellation to occur, pathlength differences on the order of the modulation wavelength must be present. As the modulation wavelength decreased relative to roundtrip tank length (for $\mathrm{f}_{\mathrm{m}}=50 \mathrm{MHz}, \lambda_{50 \mathrm{MHz}} / 2 L_{t}=0.82$; for $f_{m}=90 \mathrm{MHz}, \lambda_{90 \mathrm{MHz}} / 2 L_{t}=0.46$ ), increased cancellation of the backscatter occurred and the target contrast was enhanced. Although the contrast is degraded slightly for the 0.2 transmitter-receiver separation (Fig. 1b) due to the increased backscatter signal, the $50 \mathrm{MHz}$ and $90 \mathrm{MHz}$ data produced better contrast than either the DC or $10 \mathrm{MHz}$ data.

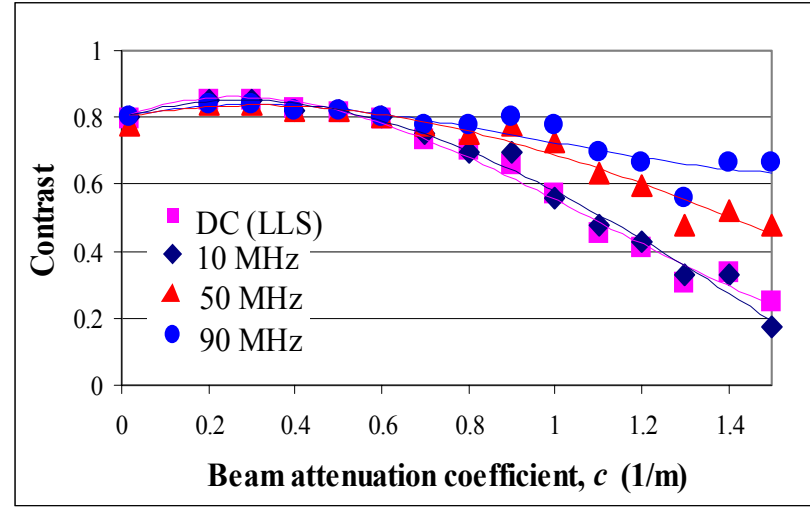

(a)

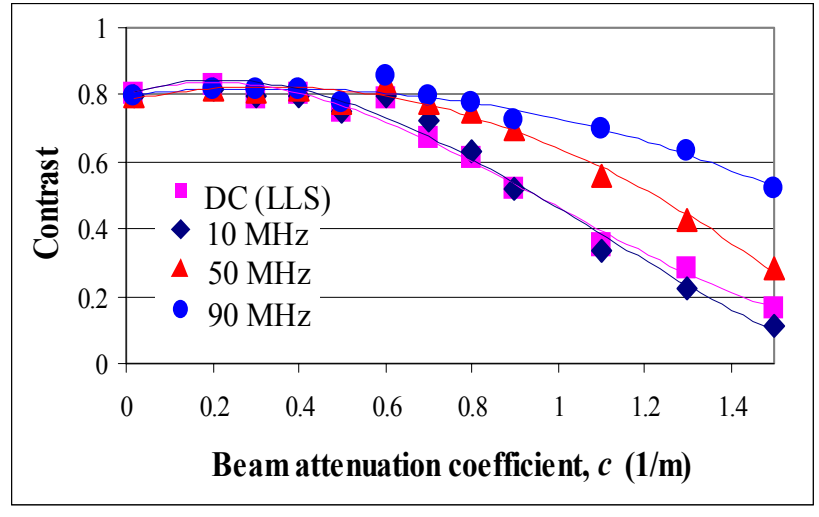

(b)

Fig. 1. Target contrast as a function of beam attenuation coefficient and modulation frequency for transmitter-receiver separations of $0.4 \mathrm{~m}$ (a) and $0.2 \mathrm{~m}$ (b). 
The next set of results in Fig. 2 shows the effect of increasing ambient light levels on the target contrast. The curves for 'L0' are those calculated for no ambient light (same as Fig. 1) and the curves for 'L1' through 'L3' represent the effect of increasing ambient light levels. The modulated signal contrast remained the same for all the ambient light levels tested and for all three modulation frequencies. However, the DC contrast decreased as the ambient light level increased and as the water clarity decreased. These results show that all three modulation frequencies are equally effective in rejecting ambient light.

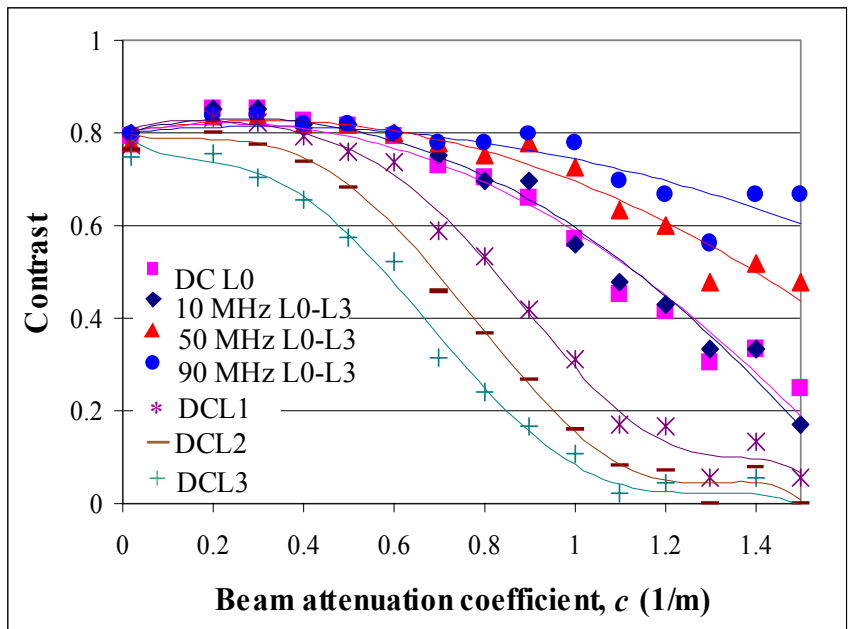

(a)

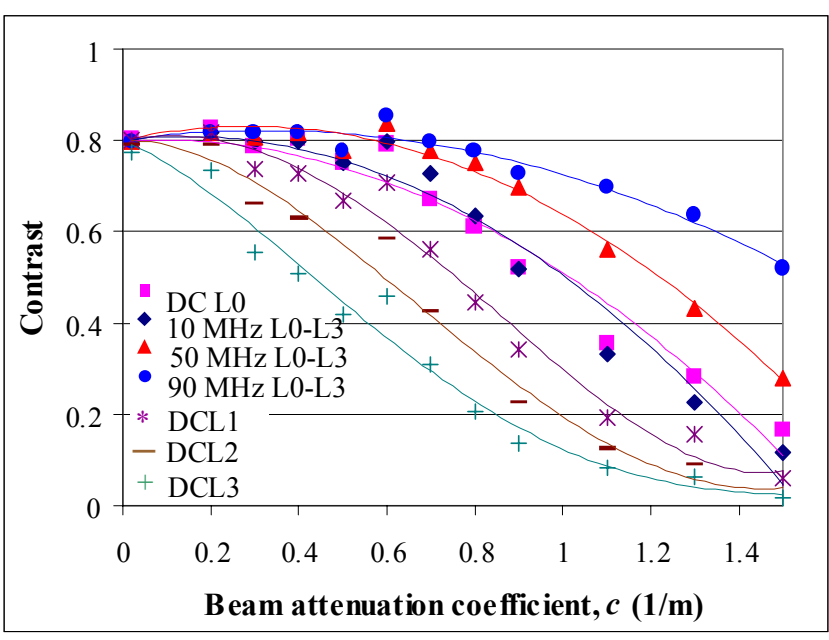

(b)

Fig. 2. Target contrast as a function of beam attenuation coefficient, modulation frequency, and ambient light level for transmitter-receiver separations of $0.4 \mathrm{~m}$ (a) and $0.2 \mathrm{~m}$ (b).

In Fig. 3, the target range data calculated from the modulation phase measurements is plotted against the beam attenuation coefficient for transmitter-receiver separations of $0.4 \mathrm{~m}(\mathrm{a})$ and $0.2 \mathrm{~m} \mathrm{(b)}$. The dashed line indicates the true target location $(3.66 \mathrm{~m})$. For both cases, the target range calculated from the $10 \mathrm{MHz}$ data showed an increasing bias towards shorter depths as the beam attenuation coefficient increased. This is due to the fact that at this modulation frequency, the target return phase was a combination of the target itself and the accumulated backscatter signal. As the water clarity decreased, the integrated backscatter phase dominated over the target phase and resulted in an incorrect prediction of the true target range. This range error increased as the transmitter and receiver were moved closer together (Figure $4 \mathrm{~b}$ ). However, at modulation frequencies of $50 \mathrm{MHz}$ and $90 \mathrm{MHz}$, the target range error was less than $0.1 \mathrm{~m}$ over the full range of water clarities tested. These results show that a more precise estimation of the true target range is obtained with the higher modulation frequencies.

To illustrate the impact that the phase information has on the modulated EOID performance, measurements were made with a three dimensional target. A $30 \mathrm{~cm}$ long by $2.5 \mathrm{~cm}$ wide by $3.8 \mathrm{~cm}$ deep black bar was attached to the middle of the black target used in previous measurements. The bar was then scanned across the transmitted beam and receiver field of view. The DC amplitude and AC amplitude and phase information were recorded for successive target positions. The results are shown in Fig. 4 for modulation frequencies of $10 \mathrm{MHz}$ and $70 \mathrm{MHz}$ and for a beam attenuation coefficient of $0.6 \mathrm{~m}^{-1}$. In Fig. 4a, the amplitude data (normalized relative to the reflection from the bar center) was low for the three cases shown. However, the modulation phase results (shown in Fig. 4b) provided more information about the target structure and therefore improved the target contrast. The results also showed an increase in range resolution as the modulation frequency increased. 


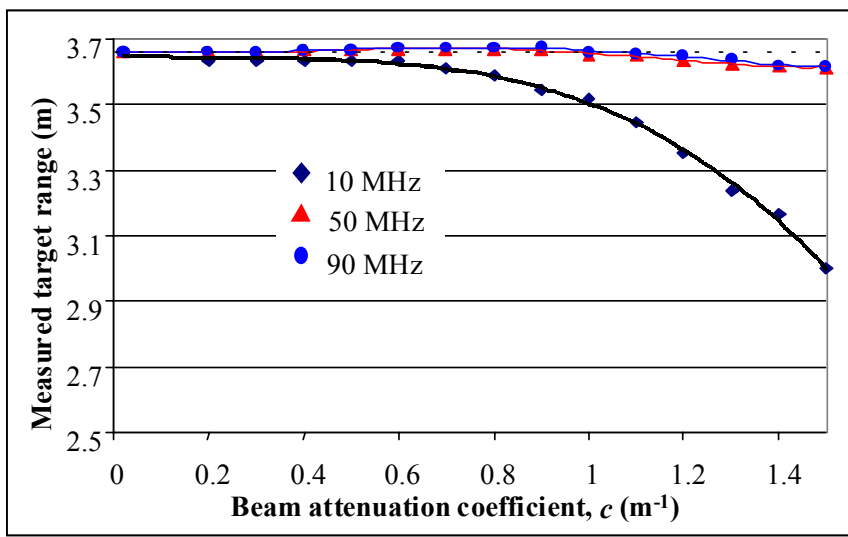

(a)

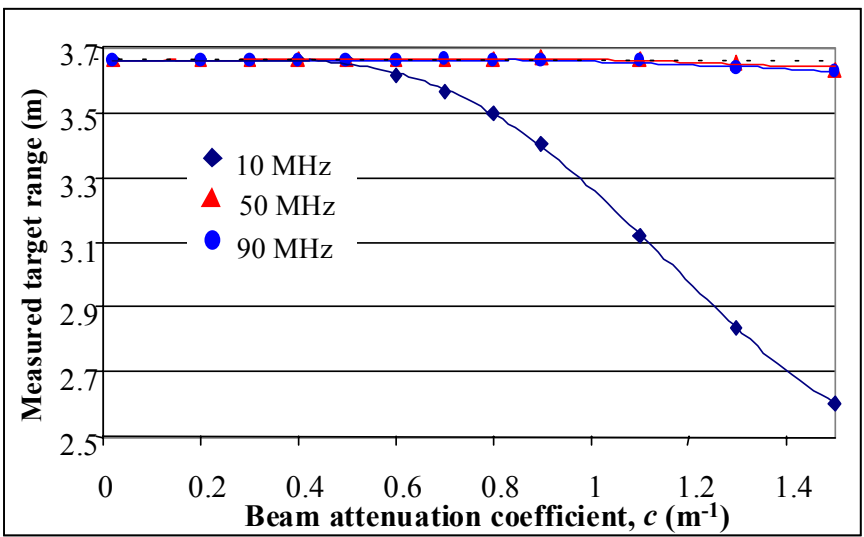

(b)

Fig. 3. Target contrast as a function of beam attenuation coefficient, modulation frequency, and ambient light level for transmitter-receiver separations of $0.4 \mathrm{~m}$ (a) and $0.2 \mathrm{~m}$ (b).

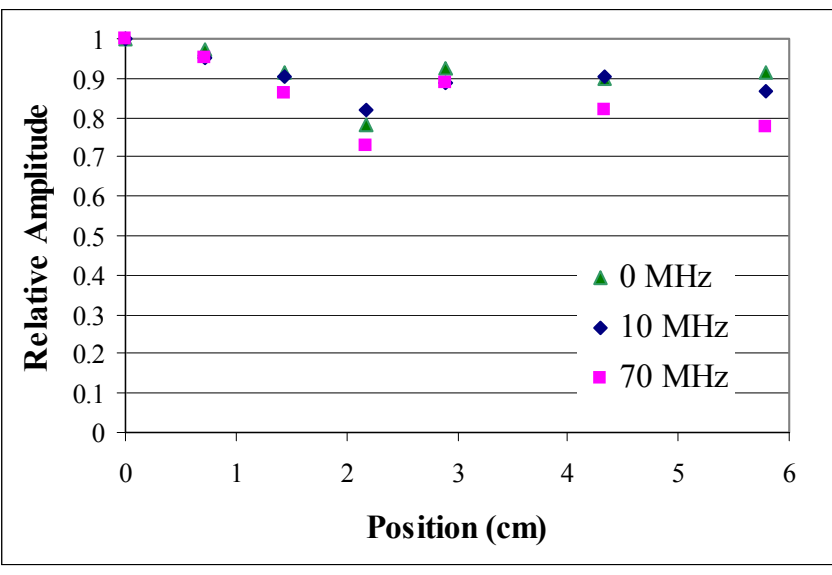

(a)

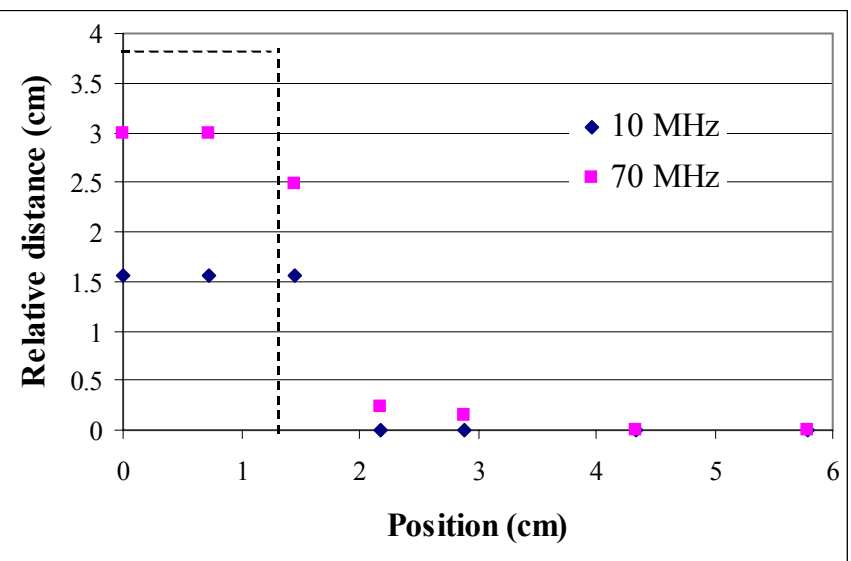

(b)

Fig. 4. Amplitude (a) and phase (b) information for the raised target experiment. The dashed line in (b) indicates the actual depth (y-axis) and width (x-axis) of the raised bar.

A summary of the results of the laboratory tank experiments is:

1. The $10 \mathrm{MHz}$ data showed no improvement in target contrast over the unmodulated data. This was due to the fact that the backscatter was still modulated at this frequency.

2. As the modulation frequency increased, the target contrast improved due to backscatter demodulation.

3. Although the unmodulated target contrast decreased with increasing solar ambient levels, the modulated contrast was unaffected.

4. The modulation phase measurements showed that while the $10 \mathrm{MHz}$ range data was adversely affected by the backscatter signal, the $50 \mathrm{MHz}$ and $90 \mathrm{MHz}$ data provided an accurate estimation of target range within $0.1 \mathrm{~m}$ for all water clarities.

5. The modulation phase information can be used to improve the detection and characterization of low contrast targets.

These results were obtained with transmitter-receiver separations of $0.4 \mathrm{~m}$ (current EOID setting) and $0.2 \mathrm{~m}$. This indicates that the EOID sensor size can be reduced when the hybrid technology is 
implemented. Although a clear preference for the higher modulation frequencies existed for improving target contrast, all modulation frequencies were shown to reject solar background noise.

\section{IMPACT/APPLICATIONS}

The laboratory experimental results show that the hybrid lidar-radar technology has the potential to impact the EOID sensor by

1. improving the sensor performance in turbid water, high solar background environments where the system is currently contrast limited;

2. adding a target range capability to detect low contrast targets; and

3. decreasing the size/weight of the current system to make it more adaptable to autonomous underwater vehicle deployment.

In the future, more advanced system configurations (i.e., higher modulation frequencies) have the potential to improve sensor performance by further decreasing backscatter noise, reducing forward blur/glow scatter noise, and enhancing target range resolution.

\section{TRANSITIONS}

The laboratory experimental results are being implemented by the CSS/Raytheon team to design future EOID sensor packages. Modulation components will be added to the EOID sensor in FY00 and FY01 and tests will be conducted to compare modulated and unmodulated underwater images. The results are also being used by CSS to validate Monte Carlo simulations that predict EOID sensor performance.

\section{RELATED PROJECTS}

The CSS/Raytheon EOID sensor project funded by ONR is closely linked to this program. Information is frequently exchanged between these programs to understand the characteristics of the existing EOID sensor so that the modulated components can be smoothly transitioned to the sensor package. The other closely related project is that which includes Drexel University. Dr. Peter Herczfeld at Drexel is supervising work in advanced component development for future modulated laser line scanner systems, including high speed detectors and high frequency optical modulators.

\section{PUBLICATIONS}

L. Mullen, V. Contarino, A. Laux, B. Concannon, J. Davis, "Modulated laser measurements in simulated ocean water: experiment and theory," Proceedings of Ocean Optics XIV, Kailua-Kona, HI, Nov. 10-13, 1998.

L. Mullen, V. Contarino, A. Laux, B. Concannon, J. Davis, “Application of hybrid lidar-radar technology to a laser line scan system," Proceedings of the 1999 Conference on Lasers and Electrooptics, Baltimore, MD, May 23-28, 1999.

L. Mullen, V. Contarino, A. Laux, B. Concannon, J. Davis, M. Strand, B. Coles, "Modulated Laser Line Scanner for Enhanced Underwater Imaging," Proceedings of the SPIE Annual Meeting, July 1823, 1999.

L. Mullen, "Modulated Lidar System for Underwater Detection and Imaging," Invited paper submitted to the April, 2000 special issue of U. S. Navy Journal of Underwater Acoustics (JUA(USN)) for ASW investigations. 


\section{PATENTS}

L. Mullen, V. M. Contarino, P. R. Herczfeld, Modulated Lidar System. (U. S. Patent No. 58,220,477, 13 October, 1998.) 